\title{
Positivism and political obligation
}

\author{
ANDREAS CH. TAKIS
}

Associate Lecturer, Athens Law School, Greece

\section{Introduction: the rule of recognition and its philosophical motivation}

\begin{abstract}
A
$\mathrm{s}$ is well known, modern analytical legal positivism, contrary to its empiricist and utilitarian predecessors, does not aim to reduce the attitudes of legal practitioners to mere behavioural and/or psychological regularities that are generated by habitual obedience to the commands of a sovereign. Rather, it focuses on what it takes to be the non-reducible "internal" normative dimension of the legal phenomenon. It does this by attempting to bring out what is distinctive about the practical reasons by virtue of which those attitudes and behaviours are given a characteristically legal justification. When we say that we are under a legal duty to do such-and-such, we mean to say that, regardless of whether the content of the duty is under the circumstances a useful, prudent, or morally good thing to do, the mere fact that it is required by law is a special kind of reason for us to comply with that requirement.
\end{abstract}

According to an influential trend in modern analytical legal positivism, the ground for such legal reasons is the rule of recognition, a conventional rule setting out criteria that determine which standards count as binding legal rules. Legal rules derive their validity from the rule of recognition, by virtue of the fact that they satisfy its criteria, but the ground of the rule of recognition itself cannot be a further, even more fundamental rule. For that would involve us in an infinite regress. ${ }^{1}$ Rather, the rule of recognition is grounded in the fact that it is accepted and practised by the members of a certain group. This raises the following question: how can the existence of a general, more or less stable social practice have the binding force of a fundamental but still legal rule? How can that practice be anything more than a happy coincidence, the contingent and provisional congruence of purely personal maxims or of concurring but independent moral views? As Hart himself stressed, for the rule of recognition to be a rule and indeed a conventional rule, it must be the case that at least those charged with enforcing the standards flowing from it treat their practice as providing them with "a public, common standard", and not a standard "which each judge merely obeys for his own part only". ${ }^{2}$ In this essay I wish to explore further the nature of the rule of recognition, in order to give a satisfactory answer to the following

1 S J Sharpiro, “On Hart's way out" in J Coleman (ed.), Hart's Postscript: Essays on the Postscript to the Concept of Law (Oxford: OUP, 2001), pp. 149-91.

2 H L A Hart, The Concept of Law 2nd edn (Oxford: Clarendon 1997), p. 116. 
questions. What are the conditions under which a social practice gives rise to public, common standards? And, in particular: what kind of connection between law and morality, if any, must we presuppose in order to explain the special normative force that the rule of recognition acquires over those who follow it?

Before I proceed to elaborate on the nature of this conventional rule, I wish to highlight two traditional strands of philosophical motivation for anchoring the study of the theory of law in the doctrine of the rule of recognition. The first strand is substantive. It has to do with the central tenet of all legal positivism, namely that law is a matter of social fact. The second is meta-ethical. It concerns the nature of the explanation of law's normativity. Let me start with the substantive motivation first.

According to the theory of Hart and his followers, the complex social fact of an active acceptance of the rule of recognition within a certain population is the distinctive mark of the existence of a legal system. Thus, while it accords with Kelsen's pure theory of law in that it preserves the hierarchical structure of legal norms, Hart's theory departs from it in that it attributes their unity and normative character to the empirically ascertainable social fact of a certain practical stance holding sway in a population and not to the mysterious according to analytical legal positivism - entity of the Grundnorm. This shift aspires to bestow upon the legal phenomenon the ontological clarity of a social fact.

Now, let's move on to the meta-ethical motivation. This motivation can be traced back to the developments in the philosophy of language commonly associated with the later philosophy of Ludwig Wittgenstein and with J L Austin. As is well known, from these developments there emerged a view of ordinary language as the repository of meaning within a linguistic community. According to this view, the collective linguistic practices of the community form a normative horizon that transcends the conduct of individual participants and gives it its social meaning. Thus, by appeal to those practices, we can understand, appraise and correct individual usage. Importantly, for proponents of this view, it is open to an external observer to understand and report the standards governing linguistic usage in this or that community "from without", without him or herself participating in the life of that community. The observer then assumes what has come to be called the "hermeneutical point of view". 3 The hermeneutical point of view, which combines the internal point of view with the adoption of a neutral stance toward the practices to be understood, has become the methodological model for most of analytical legal positivism. It insists, to use Hart's words, that the account of the neutral observer is a "description, even when what is described is an evaluation". 4 Through the adoption of the hermeneutical point of view, contemporary legal positivism has taken on a characteristically meta-ethical dimension. Legal theory is a neutral description, or more accurately, a "descriptive sociology", which reports the criteria actually employed by a linguistic community to determine correct use of concepts like the concept "law". However, the claims it makes seem not to be part of ordinary legal discourse. They appear to occupy a higher level of discourse.

We now turn to law. The primary use of the normative language of law consists of internal legal claims, that is, claims that are being made by someone who holds that legal standards govern his or her conduct. Parasitic upon this primary use is the use of normative language for the purpose of making detached legal claims. These are the claims that someone makes as if adopting the internal point of view. It is this stance that the external observer

3 The term appears in P M S Hacker's "Hart's philosophy of law" in P M S Hacker and J Raz (eds), Law, Society and Morality (Oxford: Clarendon, 1977), pp. 9ff. It is then employed by N MacCormick in his H L Hart (Stanford, California: Stanford UP, 1981), and finally adopted by Hart himself in Essays on Bentham (Oxford: OUP, 1982) p. 14.

4 Hart, The Concept of Law, p. 244. 
assumes when reporting that a rule is a valid legal rule in this or that legal system in the sense that it satisfies the criteria of validity that the linguistic community employs.

The availability of the hermeneutical point of view - the ability to understand the attitudes of other people, as they view them, without necessarily accepting or endorsing them - is the key for the positivistic distinction between the law as it is and the law as it should be in its modern guise. Even if the reasons those who accept a rule invoke in their internal claims are moral, the fact that they manifest this attitude is a complex social fact. We can analyse and even simulate this attitude by making detached judgments. What is more important for legal positivism, the detached analysis of legal discourse presumably enables legal theorists to analyse legal systems without taking sides on whether there really is an objective moral reason to comply with the law as it is in a certain legal system. If this is true, it means that one can, at the same time, assert that there exists a legal rule whereby "we ought to $\phi$ ", or that from the standpoint of the law "one ought to $\phi$ ", and that nonetheless "we have no moral duty to $\phi$ ", or even that "we have a moral duty not to $\phi$ ". There is, so the argument goes, no contradiction between the two propositions. Even the criticism of existing law, it seems, presupposes the neutral meta-ethical point of view. For, arguably, it is this point of view that makes it possible to ascertain the existence of the legal rule whose reform or repeal we champion.

Obviously, the success of the legal positivist story doesn't depend solely on the abstract possibility supplied by the hermeneutical point of view to make morally neutral descriptions of other people's practical attitudes. It must also be the case that the adoption of the hermeneutical point of view helps us account, in a manner congruent with our basic moral intuitions, for salient features of legal practice; more specifically, for the fact that the law claims the compliance of legal subjects with its requirements, in other words for its normative character.

What kind of resources we need to bring in to explain the normative character of law and whether the detached hermeneutical point of view lives up to this task are two questions that figure prominently in this article. Leaving them aside for the moment, it is now important to stress the way in which the notion of the hermeneutical point of view has been taken by legal positivists like Hart to motivate the doctrine of the rule of recognition. First, it is not hard to see how the idea that the practice of a community gives rise to standards that govern the behaviour of individual participants is at work in Hart's conventionalist account of law. Second, since the criteria for membership in law are determined by the collective practice of legal practitioners, arguably, all the legal theorist needs to do is to "describe" the practice in order to uncover those criteria, without at the same time passing any judgment on the moral merit or demerit of the practice.

\section{The idea of a public, common standard}

\section{A IDENTITY}

So, let's repeat our question: what conditions must be fulfilled for the settled practice of a group to constitute a rule in the sense of a public, common standard? To begin with, it must be the case that the behaviour of participants in the practice be perceived by the group, and by individual participants, as in conformity with a common standard. This means that all participants take it upon themselves to act on the same reason, namely the conventional rule, and that they are commonly understood as acting on that reason. In this sense, the standard is indeed common and public, at least in a weak sense, since everybody is understood to comply with it and everybody is aware that everybody else acts and thinks in the same way. Note though that the criterion of identity in itself does not preclude that, 
although all participants are commonly understood as adopting that standard, each of them adopts it because he or she thinks that it is morally good or useful or, for some other idiosyncratic reason, wise to act on that standard.

\section{B RECIPROCITY}

A further feature of the rule of recognition is that each participant takes him or herself to observe it, thus actively accepting it, by virtue of the social fact that there exists a common practice within the group, that is, by virtue of the social fact that everybody else takes him or herself to be doing the same thing.

This condition of reciprocity in the practical attitudes of participants, that is, the dependence of everyone's participation in the common practice on the fact of everyone else's participation, is what renders the rule of recognition a conventional social rule. It is this condition that precludes the possibility that the convergence of behaviour is merely a manifestation of an overlap of concurring but independent individual moral views or even of self-interested prudence. Individual participants are not only aware that they all act on the same reason, but they also take this fact to be their reason to do their share. Thus, the rule of recognition is binding by virtue of the fact that it is common and public, that is, it is a rule that each participant individually and all participants collectively follow. Thus understood, the rule of recognition, being the foundation of the legal system, makes each participant individually and all of them collectively the ultimate source of legal authority.

\section{MORAl Character}

The understanding of the rule of recognition in terms of reciprocity advanced in the previous section may seem to be too demanding for some legal theorists. For instance, Hart, to whom we largely owe this way of conceiving of law as a social phenomenon, that is, in terms of a social convention, seems to be content with a much weaker set of conditions for the rule of recognition. He insists that, for the rule of recognition to take hold, there need only be some pattern of convergent behaviour coupled with an attitude of acceptance. The kind of motive or reasoning that has generated this attitude is not crucial. For him, any practical stance that justifies acceptance in the eyes of an individual participant is as good as any other. That practical stance may be one of full endorsement but, often, it is merely one of weak acceptance. ${ }^{5}$ A person accepts a standard weakly even if he or she is guided by it out of prudence or other non-moral reasons. Hart would therefore deny that compliance with the rule of recognition is something that each participant owes to everybody else, as was argued above. Compliance, he would maintain, may well be dictated by the belief that doing as everybody else does seems attractive or mandatory to a participant from some idiosyncratic or even self-interested viewpoint.

Such weak acceptance may indeed be sufficient for grounding other social rules, like rules of etiquette, but it is utterly inappropriate as a foundation of the legal system. Law is a coercive order that imposes duties on those to whom it is addressed, also assigning a group of people the power to coerce others into compliance. If the practical force of legal duties were grounded in non-public, idiosyncratic practical viewpoints, then nobody would be warranted to demand compliance. Something very important would then be missing. Legal statements are not only statements of what I ought to do under the law. Sometimes they aim to convey what others ought to do under the law. In the case we are examining, we could not make statements of the latter kind in order to demand some sort of behaviour from another participant or dictate some sort of behaviour to him or her. At best, we could 
make such statements in order to report in a detached fashion what a person ought to do from their own perspective, or perhaps in order to give that person some practical advice. This is a point well made by Raz:

The crucial point is that much legal discourse concerns the rights and duties of others. While we can accept the law as a guide for one's own behaviour for reasons of one's own preferences or of self-interest one cannot adduce one's preferences or one's self-interest by themselves as a justification for holding that other people must, or have a duty to, act in a certain way. ${ }^{6}$

Raz concludes: "To claim that another has to act in my interest is normally to make a moral claim about his moral obligations." 7

Hart's response to this is that it is possible for a person to invoke the rights and duties of someone else, although, when that happens, the first person does not intend to say anything about what that other person ought to do. This is, according to Hart, the technically confined way in which judges speak in the exercise of their adjudicatory duties. To try to bring Hart's point home, let me employ the well-known "no-hat-in-church" example. Imagine the members of the community who follow this rule or the sexton of the church pointing out to a newcomer or absent-minded parishioner who enters the church wearing a hat that it should be removed by virtue of the no-hat-in-church rule. Imagine further that, when asked by the newcomer whether there really is any reason to remove the hat, the members of the community respond: "Not at all! What you ought to do is your own business. We didn't tell you to remove your hat because you ought to, but because, since we accept such a rule, your entering with your hat on gives us a reason to tell you what we did."

Such a response would surely sound artificial or even absurd in the context of a small parish. But maybe it doesn't sound so absurd in the context of a modern political community, in which state functions have acquired a strongly technical and bureaucratic character. This kind of sceptical or distanced attitude is in fact all too common in societies where politics has lost much of its appeal. Needless to say, nothing precludes that such an attitude could also be found amongst those who are entrusted with the administration of the law. Now, when it is ordinary citizens who manifest this attitude, this may only give rise to a concern on the part of those who yearn after a romantic and possibly authoritarian past. By contrast, when we think of legal officials who find themselves under its grip, we are more likely to treat this as symptomatic of a serious flaw in the way those officials understand their institutional role.

Of course, the point I am trying to make is not about political alienation in modern mass democracies, but about whether the attitude of a judge, who - upon rendering a decision shrugs his or her shoulders and tells the accused "I'm just doing my job", can count as acceptance of the rule of recognition in the context of a theory of law. And further, even if this kind of attitude might be taken to count as a weak form of acceptance, as Hart insists, the more crucial question is whether the acceptance of the rule of recognition can be based exclusively on such an attitude. For, by maintaining that according to his own brand of positivism no type of practical reason - and especially no moral reason - is necessarily linked to the idea of the law, Hart is committed to the idea that there is a possible world where the acceptance of the rule of recognition and ultimately the existence of law can be exclusively a matter of weak acceptance, and not at all based on moral reasons.

6 J Raz, "The purity of the pure theory", in R Tur and W Twining (eds), Essays on Kelsen (Oxford: Clarendon Press, 1986), pp 92-3.

7 Raz, "The purity", p. 93. 
Perhaps one could envisage, as Raz urges, a possible world where neither legal subjects nor the officials of the legal system assign any real moral value to the project of sustaining legal practice, but where both legal subjects and officials by and large carry on following it merely pretending that they assign it some moral value. ${ }^{8}$ Although the institutional life of such a political community would look more like a sad parody, this image doesn't seem to be far removed from the actual historical experience of political systems on the brink of total collapse or radical change. Hart, however, invites us to go even further than that. He invites us to envisage a world where, on the one hand, nobody - not even those entrusted with the administration of the law - believes in the moral merit of sustaining the rule of recognition and, on the other, there is public knowledge on the part of practitioners that this is so. ${ }^{9}$ But such a world would definitely strike us as totally alien.

To ground and sustain the practice of following a public and common standard in the stronger sense that is suggested by our day-to-day use of normative language, participants need to share something stronger than this. They need to share the belief, first, that they all have the same practical reason to follow the common practice (that is, the same reason actively to accept the rule of recognition); and, second, that this fact (namely that everybody acts for the same reason) gives each of us at the same time a reason to do what everybody else does. This dual condition is encapsulated in the ideas of identity and reciprocity analysed above. From this it follows that at least those who invoke that reason think that it is a reason that applies to everyone within the group regardless of any individual's desires or any other peculiarities in the structure of individual preferences. In other words, they take this reason to be in some sense categorical or objective. They take themselves and are commonly understood by others to be under a duty to participate in the common practice by virtue of the fact that everybody else in the group takes him or herself to have the same duty for the same reason. By the same token, each one takes others in the group to be under the same duty, given that they find themselves in the same circumstances.

Let me pause here to recap the conclusion of the foregoing analysis. It was argued that a standard is public and common if and only if those who adhere to it believe that they have a moral reason to do so by virtue of the fact that everybody else adheres to it because they think that they have moral duty to do so. Thus, the reason to comply with the standard is not a reason that just happens to be shared by all participants but a reason that, given that everybody takes him or herself to have it, is one that everybody ought to have. In other words, it is a categorical, moral reason. At the basis of this view lies the image of a social practice that legitimates itself over time. This self-legitimisation is not possible in a practice that is produced by the mere coincidence of idiosyncratic maxims but only in a cooperative enterprise that stretches over time, whose terms are taken by participants to be in a sense morally binding. Playing by the rules of the practice, and also by the rules validated by the practice, is a special duty, ${ }^{10}$ a duty that each participant owes in principle qua member of a certain group constituted by the acceptance of the rule of recognition. It is also a duty that each participant owes to every member of the group and only to them. Finally, it is a personal duty because it is owed to each member of the group individually, precisely by virtue of the fact that everyone else is also a member. The relationships between the members of the group as participants in the cooperative enterprise of law constitute the public sphere.

8 J Raz, The Authority of Law (Oxford: Clarendon Press, 1979).

9 G J. Postema, "The normativity of law" in R Gavison (ed.), Issues in Contemporary Legal Philosophy: The influence of H L A Hart (Oxford: Clarendon Press, 1987) pp. 81-104, p. 100. Hart doesn't explicitly contemplate this consequence of his view. But one can infer from a number of remarks that he is willing to accept it. For even Raz's imagined legal system of widespread hypocrisy seems to him to compromise his commitment to the total conceptual independence of acceptance from the reasons for it. See Hart, Essays on Bentham, pp 158, 256.

10 On special duties, see R Dworkin, Law's Empire (London: Fontana, 1986), pp. 195-206. 
This is the sphere where their common life, that is, the life of a political community, takes place. Participants express their moral commitment to carry on this cooperative enterprise with their use of normative language when they exchange recommendations and criticism.

As we saw, this commitment is of a special kind. It derives its moral character from the nature and terms of the cooperative enterprise that individual members actively participate in. So, when we say we have a legal duty to do $x$, we don't necessarily mean that doing $x$ is in itself a morally attractive course of action but that we have at least a prima facie moral duty to do $x$ just by virtue of the fact that this duty is dictated by law. We imply that, at least from the point of view of those who are members of the political community, the existence of a legal duty to do $x$ is morally justified, in the sense that it passes certain tests that the members of the political community jointly treat as morally appropriate. Thus, the analysis of the practical attitudes of participants in legal practice suggests that a strong notion of legitimacy lies at the very core of law. The law necessarily claims that it is morally right. And even if, in fact, it isn't, it must pretend to be right, whatever one takes "morally right" to mean.

\section{The complex neutrality of modern analytical legal positivism}

H L A Hart, we have seen, refuses to embrace the conclusion of the foregoing analysis for fear that it might lead him to adopt views also espoused by his theoretical opponents. However, the acceptance of this weak conceptual link between law and morality leaves other legal positivists undisturbed. This is because the latter harbour more confidence in the descriptive dimension of the hermeneutical point of view. For them, the aforementioned conceptual link does not concern morality but ethics. ${ }^{11}$ That is, they maintain that for a set of standards of action to add up to law it is necessary but also sufficient that a group of people believe or pretend to believe that it is morally required of them to comply with it. But it is not necessary that this belief is also true. In this way, legal positivism seems to preserve its ability to analyse legal phenomena without presupposing any substantive moral view.

Note though, that, thus understood, legal positivism is supposed to be neutral in two respects. On the one hand, the truth of its claims is supposed to be independent of the truth of any particular moral view. Let's call this type of neutrality first-order moral neutrality. This, you may recall, has the following consequence: from what, according to legal positivism, is law nothing follows in principle about what we ought to do, morally speaking. On the other hand, the neutrality of modern analytical legal positivism is of a meta-ethical character. The truth or falsity of its claims is not only independent of the truth of any particular moral view: in addition, it is independent of the question of whether there is any moral truth. Hence, it is intended to be compatible with moral relativism and even certain forms of scepticism like quasi-realism. It seems only to exclude mechanistic and more generally reductivist accounts of normativity. For these reasons, I will state that the neutrality of legal positivism is complex.

\section{Modern analytical legal positivism: more committed than it can stand}

So, despite the recognition of a conceptual link between law and morality, it would seem that the meta-ethical neutrality of modern legal positivism, which is arguably made available by the hermeneutical point of view, ensures the "descriptiveness" of its claims. In the rest of this essay, I intend to challenge the meta-ethical neutrality of the hermeneutical point of view and with it the neutrality of modern legal positivism, starting from the account of the rule of recognition expounded in the previous section. I will claim that the meta-ethical

11 For a classical statement of the distinction between the moral and the ethical, see P Strawson, "Social morality and individual ideal" (1961) 36 Philosophy 4ff. 
neutrality by itself does not suffice to guarantee the distinction between law as it is and law as it should be, if it is not complemented by its first-order moral counterpart. And in the case of the version of legal positivism we are now examining, I will claim that the combination of the two types of neutrality fails.

\section{A THE NECESSARY COMBINATION OF MORAL AND META-ETHICAL NEUTRALITY}

In this section I will try to show that legal positivism needs the combined effect of moral and meta-ethical neutrality in order to stay away from what Hart has called the "jungle" of philosophical strife ${ }^{12}$ and secure for its claims the status of descriptive non-committed statements. Suppose it turns out, on the one hand, that there are objectively right answers to moral questions and, on the other, that there is a general moral obligation to obey the law. Now recall that, according to the conventionalist understanding of law in the revised version summarised above, the idea of law is conceptually linked to the fact that members of a group take their common practice as a moral reason to do their share to sustain that practice. In this case, and assuming the philosophical debate is resolved in the direction I suggested, it would follow that the same circumstances that make it true that we have a moral obligation to obey the law also make it true that there is law. For legal conventionalism of the revised type to maintain its positivistic character, however, it must be the case that in such a situation this fact is merely contingent. That is, it must be only contingently true that under the same circumstances there is law and we have a moral obligation to obey it. The crucial test for this is whether there are cases where, although the conditions for the existence of law are satisfied, the conditions for the existence of a moral obligation to obey it are not. Again, this means that there must be a possible world where a legal system is in force, whereas the moral conception or conceptions underpinning the belief of legal subjects about the moral bindingness of their collective practice are false. Otherwise, if the truth conditions of claims about the existence of law are conceptually linked to the truth conditions about the existence of a moral obligation to obey the law (on the assumption that there is moral truth), then we could entail from the fact that a legal standard is valid that we also ought to follow it, morally speaking.

\section{B WHAT IS THE "FUEL" OF LEGAL NORMATIVITY?}

Against the analysis of the previous section it may be argued that even deprived of moral neutrality the legal positivist still has one manoeuvre at his or her disposal. More specifically, it may be insisted that philosophical claims about the existence of law are made from a detached point of view. They merely describe certain complex social facts. But they don't have normative force. This response seems to sever the tie between the meta-ethical and the moral neutrality that I argued for in the previous section. It suggests that even if moral neutrality is not possible (because, say, there is only one right answer to moral questions), the legal theorist can always find resort in the meta-ethical neutrality of the hermeneutical point of view. In this and subsequent sections, I want to show that unless complemented by a robust type of moral neutrality, meta-ethical neutrality in itself is no more than mere pretence or a smokescreen whose sole aim is to conceal the failure of the positivistic enterprise.

Recall that the hermeneutical point of view presumably enables legal theorists to understand the practical attitudes of participants in legal practice without themselves passing any judgment on the truth of the moral conceptions that participants invoke to ground their belief in the existence of moral reasons that justify their practical attitudes. It is necessary

12 "Definition and theory in jurisprudence" in H L A Hart, Essays in Jurisprudence and Philosophy (Oxford: Clarendon 1983), p. 21. 
and sufficient for the existence of law in this respect that each participant is taken to justify his or her attitude, either sincerely or not, by appeal to some moral conception, even a false one. Arguably, the meta-ethical point of view imposes no constraint on the content of the moral conceptions that happen to support the crucial normative attitudes of participants. But it would be premature to infer from this that legal theory can indeed be morally neutral. Even if the meta-ethical point of view doesn't seem to privilege any one moral conception as suitable for that role, this doesn't entail that any moral conception is indeed suitable as a "fuel" of legal normativity. Quite the contrary, if a moral conception is to perform the role that the revised conventionalist understanding of law assigns to it, it must satisfy certain conditions. Thus, it must be able to present the fact that the law dictates a certain conduct as giving rise to a moral reason to adopt it. This doesn't mean of course that the moral conception must also be sound. At any rate, though, it must be such that it includes in the moral description of legal practices it offers all those circumstances that, according to the conventionalist understanding, constitute the idea of law.

Once again, against this line of reasoning the objection may be raised that we ask too much from participants in legal practice. This objection starts from the fact, often highlighted in the preceding analysis, that those who participate in the common practice need only pretend to believe they have a moral reason to sustain it, while in reality their reason is none other than purely self-interested prudence, adherence to tradition or plain imitativeness. The objection concedes, of course - as do many legal positivists - that the motives that actually drive participants are one thing and the practical reasons by appeal to which they are taken to justify their participation are quite another. But it insists that, since for legal positivists it is irrelevant whether the moral conception that participants are taken to espouse is sound, it must be equally irrelevant which moral conception more specifically they do adopt.

This reaction, however, would be out of order. It would be inconsistent both with the substantive views of modern legal positivists concerning the nature of law and with the methodology of the hermeneutical point of view. What matters according to the revised conventionalist understanding of law is not that legal practitioners are actually moved by moral reasons but that they are taken to act from such reasons. Only this kind of reasons, we have seen, can make sense of legal practice and the special normative force of legal reasons. These moral reasons constitute the internal normative horizon of legal practice, so to speak. They thus have the character of an ideal in the light of which the use of normative language by participants makes sense and is appraised. ${ }^{13}$ This means that the question about whether the moral conceptions that fuel the normativity of law must take a certain shape and, further, the question about the moral neutrality of legal positivism need to be answered at the level of ideal practical deliberation and not at the level of actual motives. In turn, the objection of the previous paragraph that states that any moral conception will do fails precisely because it falls prey to the common confusion of actual motives (an explanation of human behaviour) and reasons (its justification), which enable us to view that behaviour as having some kind of meaning for the agent.

From this point of view, a moral conception is ill suited to fuel the normativity of law, unless those who adopt it can - from within that conception - regard the duties arising

13 Cf. J McDowell, Mind, Value, and Reality (Cambridge, Mass. and London: Harvard UP 1998) pp. 104-5. 
from the common practice as morally justified. ${ }^{14}$ In the following section, I will outline the main features of a moral conception that I will claim is up to this task. That is, it is in position to account for the fact that individual participants take it that they have a duty to follow the rule of recognition by virtue of the fact that everybody else likewise accepts such a duty, this being made manifest in their common practice. The constraints that I will argue flow from this structure of legal reasons, being a special kind of moral reasons, seem to undermine once and for all legal positivism's professed moral neutrality.

\section{THE IDEA OF A FAIR SCHEME OF COOPERATION AS THE NORMATIVE FOUNDATION OF LAW}

It has so far been argued that legal reasons are a special kind of moral reasons. ${ }^{15}$ If a person has them, they do so by virtue of the special bond that ties them to a certain actual political community. Participants develop a special reflective attitude toward the practices of their political community. They regard them, even insincerely, as the manifestation of a cooperative enterprise. This, we have seen, is what it means for a group of people to treat their common practices not simply as the outcome of some form of social coordination but as a joint project governed by standards that they take to be public, common and binding on all. I have claimed that it follows from this that the binding force of these standards is categorical. Each of the participants, from the standpoint of a certain moral conception, must regard the terms of the cooperation as in principle fair. Now, the moral conceptions that inspire participants in the joint project must be reasonable. That is, they must have some internal adequacy and coherence. For, otherwise, they wouldn't really provide justification for any moral judgment. ${ }^{16}$

Let's take a closer look at the content of the attitudes participants take toward their political community. Each one of them considers him or herself to be bound to do their share in that project - namely to comply with the standards that govern it - because each person considers all the other members of the group to view themselves as likewise bound. In other words, the reason for everyone to participate in the practice is inevitably grounded (at least in part) in the moral attitude of their fellow-participants. To put it differently, fellow-participants qua moral agents are themselves the reasons for which each one ought to carry on with the practice. ${ }^{17}$ Hence, the idea of a fair scheme of cooperation exemplifies an ideal of moral reciprocity: the practice of law is the practice of mutual public recognition on the part of the members of a certain political community. To say that the cooperative practice of a certain political community is the forum where the mutual recognition of its members takes place is just another way of describing how each member must regard him

14 This seems to be the relationship Rawls envisages in his later work between the political conception of justice on which various comprehensive religious and philosophical doctrines overlap. See J Rawls Justice as Fairness: A restatement (Cambridge, Mass: Harvard UP, 2001), p. 33: "For those who hold well-articulated, highly systematic, comprehensive doctrines, it is from within such a doctrine (that is, starting from its basic assumptions) that these citizens affirm the political conception of justice. The fundamental concepts, principles, and virtues of the political conception are theorems, as it were, of their comprehensive views."

15 On taking legal reasoning as a special case of moral reasoning, compare also the Sonderfall (special case) thesis of Robert Alexy (A Theory of Legal Argumentation. The theory of rational discourse as theory of legal justification (Oxford: Clarendon 1989) and the position of Gerald Postema ("Jurisprudence as practical philosophy" (1998) 4 Legal Theory 329-57).

16 John Rawls has famously contended that the notion of a set of fair terms of cooperation as well as that of a reasonable moral conception are already included in the idea of a cooperative activity that stretches over time. See J Rawls, Political Liberalism (New York: Columbia UP, 1995), pp. 16-17; and Justice as Fairness, pp. 6-7.

17 I draw the idea of persons as categorical practical reasons in the context of a soft form of moral realism from Christine Korsgaard, The Sources of Normativity (Cambridge: CUP, 1996), p. 166. 
or herself and others from the point of view of an ideal practical deliberation: From this point of view each member accepts that it is a sufficient reason, both for him or herself and for others, to contribute to the common practice that members of the political community in general appear actively to manifest their belief that this practice constitutes a fair system of cooperation. In so doing, each member presupposes that everybody else also regards on the basis of one's own moral conception - that the terms of the practice are just and therefore binding. Thus, members of the political community are understood as participating in the practice on the basis of a belief in its fairness and bindingness.

This way of conceiving of fellow-participants implies that, in order for someone to be regarded as participant in the cooperative enterprise and to be publicly recognised as member of the political community, it is necessary and sufficient that that participation is grounded in a reasonable moral conception, according to which the common practice is presented as a fair system of cooperation which lays binding claims on the individual. That person's status as participant, though, does not depend on the content of his or her reasonable moral conception in any further way. For what is crucial in this context is not which moral conception each participant adopts or whether that conception is right, but just the fact that someone's participation is understood by him or herself and by others to be morally motivated; to flow from their having adopted a certain moral conception, according to which the common practice is presented as a fair scheme of cooperation that lays binding claims on the individual. In other words, what is crucial is someone's general capacity to form and adopt such moral conceptions and to act on them.

This reflective capacity is made manifest by one's readiness to offer arguments in defence of one's actions by invoking abstract principles, or to criticise others, and also to accept criticism as justified. An equally important manifestation of this capacity is one's willingness to modify one's moral conception and adjust one's behaviour accordingly when one is offered convincing reasons to do so. Such a change, even if it is radical, does not affect one's continued status as member of the political community. For that status depends on one's capacity to occupy a critical reflective attitude toward one's own behaviour, aims and desires, and to evaluate and modify them in the light of abstract categorical principles. In the context of the practice of law, we have seen that this capacity is further specified as the capacity to view that practice as a cooperative activity, the terms of which meet certain standards of justice, on the basis of a reasonable conception of those standards, and also the capacity actively to contribute to the continuation of the practice, by adhering to its terms. Being equipped with this effective sense of justice, as this capacity is sometimes referred to, ${ }^{18}$ is in turn typically manifested in one's tendency to make claims and, more importantly, to assume duties and other commitments that flow from the terms of the practice. But since, as we have seen, the practice itself constitutes the normative foundation of the law, the sense of justice is in essence the capacity to submit oneself under the governance of the law.

Undoubtedly, there is evident affinity between the idea of a composite reflective capacity of the kind outlined above and the idea of autonomy or moral freedom, which in the deontological tradition in moral philosophy acquires the status of a categorical property of persons. It is important to stress, however, that the argument of this essay does not depend on or flow from the truth of any particular metaphysical view on personality. The idea of the "moral powers" with which members of the political community are understood to be equipped, on which the argument of the essay does depend, is merely a reflective reconstruction of what those who engage in legal practice ought to presuppose, if legal

18 J Rawls, A Theory of Justice (Oxford: OUP, 1971), pp. 505ff.; J Rawls, “The sense of justice”, in S Freeman (ed.), John Rawls: Collected Papers (Cambridge, Mass: Harvard UP, 1999), pp. $96 \mathrm{ff}$. 
practice is to make sense: to recap, they ought to presuppose that each member of the political community, themselves included, possesses the fundamental moral powers that constitute what we have come to call moral freedom. That is, they ought to presuppose that, since they are all understood to follow the practice for moral reasons, each member is at least minimally capable of forming their own moral conception and developing an effective sense of justice.

This means that, in the context of ideal deliberation, each person carries weight in the moral judgment of another, just by virtue of the fact that he or she is regarded as a moral person, with whom cooperation on the same terms is possible. As Rawls notes: "[w]e say that a person is someone who can be a citizen, that is, a normal and fully cooperating member of society over a complete life". ${ }^{19}$ This being the only capacity in which members participate in ideal deliberation, everyone necessarily takes oneself and others to be radically equal. For, from the crucial normative point of view everyone is presumed to possess the requisite capacity.

The conclusion of the previous paragraphs is evidently supported by common experience. We typically recognise that under normal circumstances everyone above a rough age limit has the capacity for the moral powers that are necessary for full membership in the cooperative activity of law. But common experience is not a value-neutral empirical fact, which can by itself provide a criterion for selecting those from among the human species who are indeed capable in this sense. By contrast, common experience merely reflects our practices of mutual recognition. ${ }^{20}$

Hence, moral freedom and equality determine the special standing of persons in the context of ideal practical deliberation. At the same time, they constitute the moral reason that gives rise to a prima facie political obligation: From the ideal standpoint of justification, only persons who cooperate under conditions of freedom and equality may be, each one of them and all of them together, the source of moral authority and commitment. In this way, freedom and equality become the building blocks of the idea of a fair system of cooperation, which specifies, as we have seen, a notion of reciprocity, which is, in turn, constitutive of the idea of a categorical social rule. A term cannot be fair and therefore binding unless it guarantees freedom and equality, as understood above, between members of the political community. Thus, the conception of law as a fair scheme of cooperation models the framework of acceptable constraints on the content of the terms under which someone can have a political obligation. ${ }^{21}$ Nonetheless, these constraints, however thick, do not uniquely determine a particular moral conception. Both our experience and the intellectual universe of religious and moral ideas can provide us with examples of conceptions that pass the test, while being as diverse as, for instance, natural law humanism and the anthropocentric theology encapsulated in the phrase "in His own image". Not all conceptions pass the test, though. So we have to exclude aristocratic or theocratic conceptions, insofar as they presuppose a hierarchical structure in society, as well as conceptions that deny moral personality to members of certain segments of the population. The same applies to many

19 Rawls, Political Liberalism, p. 18.

20 A persuasive account of such mutual recognition practices could be given along the lines of Donald Davidson's idea of radical interpretation. See, e.g. his "Psychology as philosophy" in Essays, Actions and Events (Oxford: Clarendon 1980) pp. 229 ff.

21 Rawls, Justice as Fairness: "[The device of the original position] models what we regard - here and now - as acceptable restrictions on the reasons on the basis of which the parties situated in fair conditions, may properly put forward certain principles of political justice and reject others." 
versions of utilitarianism and most definitely to classical act-utilitarianism, if Rawls' famous objection against it is valid. 22

In short, freedom and equality constitute a set of fixed points on which acceptable moral conceptions overlap. Although these two ideals don't pick out a single comprehensive moral conception, they define a particular normative conception about what can count as a fair term for the cooperative activity of law, a conception of justice grounded in the equality of free persons cooperating over time. At its core, any claim made in the course of legal practice is presumed to rest on some common and public standard that is acknowledged to be binding, because it is believed to accord with the principles of justice that ought to govern the scheme of cooperation between free and equal persons over time. Thus, the idea of a fair scheme of cooperation forms the normative horizon of legal claims. To use a rather old-fashioned philosophical idiom, it is a regulative idea of Practical Reason. ${ }^{23}$

What I have so far said should not be taken to suggest that a legal system exists only insofar as its requirements conform to the principles of justice, a claim commonly attributed to natural law theorists by legal positivists. All it suggests is that it is part of the nature of law that law must at least claim to be just - as defined above - or be presented as such. ${ }^{24}$ To be sure, legal officials may be insincere, hypocritical or simply in error when they speak on law's behalf. However, a legal system that imposes or tolerates systemic discrimination in the standing of legal subjects, or a legal system that partially or totally excludes some of them from the life of the political community, or a legal system that doesn't adequately respect its citizens' moral freedom and its own institutional safeguards etc., such a legal system does not cease being a social phenomenon to which we would rightly refer as "law" or "state". 25 That's because, even when it is unjust, law still claims to be morally justified and worthy of the allegiance of its addressees. Of course, in that case its moral demerit seriously compromises its all-things-considered moral bindingness.

At any rate, the existence of this normative horizon constituted by the idea of a fair scheme of cooperation between free and equal persons implies that the effective "deep grammar" of every law is firmly grounded in a full-blooded conception of the principles of political justice. It is the bindingness of those principles that is presupposed in the participants' everyday use of normative language. Hence, in a crucial sense Hegel was right

22 Recall that, according to Rawls, utilitarianism does not take seriously the separateness of persons and instead treats them as substitutable and dispensable parts of a comprehensive system of desire-satisfaction that aims at the maximisation of aggregate utility. See Rawls, A Theory, pp. 22-7.

23 I Kant, The Metaphysics of Morals (Cambridge: CUP 1991), pp. 124-5.

24 That is why it would be deeply contradictory for a legal system to declare its unjust character, by including, for instance, such a declaration in its constitution. As is evident, I am borrowing this idea from Robert Alexy's famous thought experiment. See R Alexy, “On necessary relations between law and morality" (1989) 2 Ratio Juris $167-83$.

25 One must therefore accept that the concept "law" also refers to extremely unjust legal systems, such as those that institute slavery or put into effect an official policy of systematic extermination of a segment of the population. It must be noted, though, that the extreme injustice of such legal systems affects the scope of the prima facie bindingness of its rules. So, for example, to the extent that the political institutions of Nazi Germany are presented as just vis-à-vis those they recognise to be members of the political community, they do constitute a legal system that properly makes a prima facie claim to their allegiance. This has the following consequence: the soldier manning a gas chamber has a prima facie duty to do his share in the programme of the physical extermination of the Jewish and gypsy population and of homosexuals. On the other hand, though, the people targeted by that programme do not have such a duty because they are not addressees of law's claim. Likewise, a slave in a 5th-century BC polity didn't have a prima facie duty to be put to death. But, in the case of a free citizen, such a duty existed and - as the example of Socrates demonstrates - was sometimes willingly fulfilled. 
to say that every legal system claims to realise the Moral Idea. ${ }^{26}$ Every legal system is necessarily understood to be the institutional embodiment of a certain conception of justice.

\section{THE REJECTION OF THE OBLIGATION TO OBEY THE LAW AND ITS PRICE}

The claim advanced above that conventionalist theories of law, far from being morally neutral, presuppose a conception of justice based on equality and liberty will hardly surprise anyone but the most committed legal positivists. It may be argued, however, that, even if we accept the conclusion of the preceding analysis, all is not yet lost for the type of analytical legal positivism under consideration. For, even if it is conceded that the principles of political liberalism constitute the normative horizon of every legal system, it doesn't follow from this that these principles are also true. For legal positivists like Hart, the objection will go on, it suffices that a group of people actively accept that there exists a moral obligation to follow the rule of recognition. Whether these people hold this attitude sincerely or not is simply irrelevant. The existence of such an attitude by itself is all that a positivist theory of law is committed to. And this attitude is still an empirical fact that the theorist can ascertain, understand and report in a non-committal fashion by occupying the hermeneutical point of view.

Hence, despite having to abandon its moral neutrality, Hartian legal positivism appears to retain at its disposal its methodological arsenal, namely its meta-ethical neutrality. From the meta-ethical standpoint, it seems, the statements it makes are purely descriptive, as Hart insists. They seem not to depend in any way on critical morality. Likewise, from the same standpoint lawyers seem to be able to expound legal doctrine in Kelsen's detached fashion.

But one may wonder: what is the point of this methodological possibility, when it is not backed by moral neutrality? The answer is that there is no point. Insofar as the bindingness of propositions of law presupposes the truth of a certain conception of justice, legal theorists cannot remain agnostic and abstain from tackling the question whether there really is a moral obligation to obey the law. The very idea of neutrality implies the existence of more than one alternative. One cannot be neutral toward a single option. What then are the alternatives that a legal theorist is supposed to be neutral to, if the only available option is that there is an obligation to obey the law? To insist on not taking sides in this case seems mere pretence.

Of course, there is still one route left open for Hartian positivism: to maintain that there is in fact no obligation to obey the law. But such a strategy faces serious obstacles. First, it seems to go against the fact that most people in their daily lives make manifest their belief in the existence of such an obligation. It must therefore come up with a plausible theory of error. ${ }^{27}$

26 G W F Hegel, Elements of the Philosophy of Right (Cambridge: Cambridge UP, 1991), \ 257.

27 The burden on those who deny the existence of an obligation to obey the law to provide this kind of theory is underlined, among others, by Philip Soper, "Legal theory and the claim of authority" (1989) 18 Philosophy \& Public Affairs 209-37, and, more emphatically, by Leslie Green, "Who believes in political obligation?" in J Narveson and J T Sanders (eds), For and Against the State (Lanham Md: Rowman \& Littlefield, 1996), pp. 1-17, especially p. 5. Both reprinted in W A Edmundson (ed.), The Duty to Obey the Law: Selected philosophical readings (Lanham Md: Rowman \& Littlefield, 1999), pp. 213ff. and 301ff. respectively. Leslie Green, who belongs to those who argue against the existence of an obligation to obey the law, based on a survey of public opinion in Chicago, observes that the mass belief in a moral obligation to obey the law is rather a myth. In fact, he argues, this belief is made up of a variety of attitudes, which, though syntactically similar, have very different content. It must be stressed, however, that the nature of legal reasons is not a matter of empirical research, a matter of reporting the attitudes toward the law shared in a certain population. Instead, it is more a question of exploring the philosophical presuppositions of those attitudes. 
Let me pursue this point a bit further. The existence of an obligation to obey the law can be challenged on either meta-ethical or moral grounds. That is, one can either reject the idea of moral objectivity wholesale or accept that moral objectivity is in general possible but insist that there is no genuine moral obligation to obey the law. Of the two strategies the former seems to be no longer available to the modern analytical legal positivist of the Hartian type. For this kind of comprehensive moral scepticism will inevitably lead him to views that tend to reduce legal and in general social practice to behavioural regularities and habits of obedience. Insofar as legal positivism is committed to the independence of the internal point of view, it cannot but stay away from reductive accounts. Hence, the argument against the existence of a general moral obligation to obey the law must take the form of what Ronald Dworkin has labelled internal scepticism. ${ }^{28}$ However, internal scepticism, with regard to the obligation to obey the law, will not get us very far either. To see why, it would be useful to start once again from the fact that members of a political community commonly believe that they have a moral duty to obey the law. I am not saying that this fact on its own counts against internal scepticism. Although the discovery of an instance of mass deception or of a widespread error causes much surprise and possibly distress, this is no reason to hold onto a false belief. More important for present purposes is the connection between this common belief and the existence of law. It has been argued that the fact that each member of a political community takes upon him or herself the common practice of identifying, applying and changing law as a moral duty (and is understood by others to regard this as such) is the moral reason for everybody else to do the same thing. It has also been argued that only in this way is it possible for certain standards to acquire the categorical bindingness that our day-to-day use of normative language assigns to legal standards. If, therefore, the obligation to obey the law is shown to be nothing but ideology, this "demystification" of legal practice is bound to have wide-ranging effects.

To begin with, it goes without saying that internal scepticism with regard to the obligation to obey the law cannot be part of common and public knowledge in the political community: public recognition of the non-existence of such an obligation would automatically break the special bond upon which membership in the political community is founded. In this case the law would give rise to duties, if it did, solely by virtue of calculations of personal interest or psychological identification. As a consequence, social life would be more of an association, based on the free choice of participants, rather than a system of cooperation, participation in which is mandatory, insofar as it is taken to be fair. ${ }^{29}$

But maybe we could instead envisage a world where members of the political community participated in the common practice of identifying, applying and changing law, pretending that they did so out of a sense of duty, while in reality they believed that such a duty never existed. In this case, the belief in the non-existence of that duty would be confined to the private sphere, even if it happened to be shared by everyone. For otherwise there would cease to be a political community. This scenario, as has already been noted, is not conceptually impossible, since all the conditions for the existence of law are in place, even if the requisite attitudes are mere pretence. Still, as I argued above, what we would be faced with in this case would not be a normally functioning political community, but rather one at the brink of total collapse or radical change, whose institutional life has deteriorated into parody, since nobody believes in the justice of its terms, which nonetheless each

28 On the distinction between internal and external scepticism, see Dworkin, Law's Empire, pp. 78-85, and R Dworkin, "Objectivity and truth: you'd better believe it" (1996) 25 Philosophy \& Public Affairs 87-139.

29 In fact this is the view that Joseph Raz seems to hold in "The obligation to obey: revision and tradition" (1984) 1 Notre Dame Journal of Law, Ethics and Public Policy 139-55. 
participant himself invokes, when he demands the compliance of others. In other words, if the rejection of a general moral duty to obey the law is taken to be sound, then one is committed to saying that law has an inherent tendency either to self-effacement or to its transformation into an extremely unstable social practice, which is for this reason very unlikely to last over time.

Thus, if they were to dismiss the moral bindingness of law as mere ideology, conventionalist theories of the Hartian brand would effectively reduce the life and existence of legal systems and political communities to a practice based on the immaturity of the masses and the hypocrisy of an enlightened elite. This of course is a consequence that is hard to swallow. Yet, this is what Hart seems to have in mind when, as a justification for his insistence on not accepting a minimal necessary connection between law and morality, he points out:

[1] t seems to me to be unrealistic to suppose that judges in making statements of legal obligation must always either believe or pretend to believe in the false theory that there is always a moral obligation to conform to the law. ${ }^{30}$

But how unrealistic can the supposition be against which Hart's mistrust is directed? The presence of law is one of the most pervasive and, one might say, routine features of our everyday lives. We typically employ legal standards to appraise one another's conduct, to exchange recommendations, we invoke them to raise claims against one another and - at least in the main - abide by them, unless perhaps it is quite easy for us to avoid doing so. With our active participation in legal practice each of us is taken by others to accept the rule of recognition that governs our political community and organises our common life. In other words, these elementary attitudes and practices give rise to a presumption that all those who participate in legal practice regard law's authority as legitimate; put differently, that they treat the law of recognition and the rules validated under it as realising a conception of justice that all members of the political community embrace and accept as binding. On this point, natural law theorists as well as many legal positivists are in agreement. However, as has been argued, for this attitude (that members of the political community are taken to share) to be reasonable and coherent, it must be the case that the conception of justice that the institutions of the political community are taken to realise is made up of the principles of political justice that govern a cooperative enterprise between free and equal persons that stretches over time.

No doubt, many theorists believe that this conception of justice is deeply wrong. Even more theorists believe that the present political structure of many states is in fact unjust; and they may be right. But, however this may be, it doesn't change the fact that, if we want to conceive of legal practice as having a point and some internal coherence and not merely as raw behavioural data, we must suppose that it is taken by participants to constitute a fair scheme of cooperation between free and equal persons. This, we have seen, is the inescapable grammar of legal practice. So, regardless of who in fact believes in a moral obligation to obey the law or in the justice of the legal system, our social practices that supervene on the patterns of convergent behaviour establish the mutual recognition of members of our political community as persons and fellow-participants. By interpreting practitioners' behaviour as a manifestation of their active participation in a fair system of cooperation, we attribute to each practitioner - ourselves included - the status of a person equipped with the moral powers that are necessary for one's full participation in the common life of a political community. In this way, each one of us individually and all of us together form a public or political personality that transcends our fluctuating psychological

30 Hart, Essays, p. 10. 
dispositions and personal views. Because it abstracts from contingencies, this personality provides an appropriately stable foundation of one's membership in the practice of mutual recognition and is capable of making each one of us an equal bearer of the moral authority of law. From this viewpoint, the coercive nature of law, its ability to bind us "externally", is merely a manifestation of the categorical force of being a free and equal member of the political community. 31 That is, it flows from the fact that moral persons are themselves capable of constituting "external" practical reasons, namely reasons that are objective and independent of our actual psychological dispositions.

So, when someone, by actively participating in legal practice, acknowledges their moral obligation to obey the law, that person is at the same time taken to accept all other participants, including him or self, as persons who are equally equipped with moral powers. Likewise, the individual's participation allows others to treat that person as a moral person. An analogy may be of some use here. When we sympathise with someone who is suffering, we treat him or her as a person and at the same time we allow others to treat us as someone who is capable of understanding what pain means. In the same vein, the recognition of a moral obligation to obey the law is part of what it means to be a moral person. ${ }^{32}$

So, if we deny a prima facie moral obligation to obey the law, we necessarily give up on our participation in the practice of public mutual recognition between moral persons. We prove ourselves unwilling to conceive of those with whom we cooperate in the context of our common political life as anything more than mere obstacles or means in our strategic calculations. No doubt, we do adopt this kind of attitude from time to time. However, its consistent and systematic adoption would deprive us of the possibility to ascend through the reciprocity of recognition to the status of person. Even more important than our social standing as persons, this attitude of a moral Robinson Crusoe would deprive us of our capacity to transcend in reflection our various experiences and to view ourselves as a self, a unified subject of perception and action among other subjects. ${ }^{33}$ Our mutual recognition as persons and moral reasons for action is not an attitude that we choose but "simply what we do".34

Thus, Hart was wrong to claim that a general moral obligation to obey the law is unrealistic. In a sense, what is unrealistic is to deny the existence of a moral obligation to obey the law merely in order to avoid having to concede the moral presuppositions of the existence of law. The rejection of the categorical bindingness of the prima facie obligation to obey the law or its explanation in terms of an optional identification with a certain group, insofar as they deny the mutual recognition of those who coexist in a political community as moral persons, contradict something that each of us does and cannot but do. In view of

31 On the idea of external legislation and the fundamental distinction between duties of justice (officia juris) and duties of virtue (officia virtutis) that is made possible by this idea, see Kant, Metaphysics, pp. 64-5.

32 In the same vein, Rawls writes that the acceptance of a duty of fair play "is a necessary part of the criterion for their recognizing one another as persons with similar interests and capacities", "a reflection in each person of the recognition of the aspirations and interests of the others to be realized by their joint activity" "Sense of justice", p. 62). Rawls also suggests the analogy between compassion and the duty of fairness, which he derives from a reading of certain remarks made by Wittgenstein regarding the idea of pain and private language.

33 Jürgen Habermas famously argues for the impossibility of moral solipsism ("Diskursethik: Notizen zu einem Begründungsprogramm" in J Habermas (ed.), Moralbewußtsein und kommunikatives Handeln (Frankfurt a M: Suhrkamp 1983), pp. 53-125). Drawing on the later philosophy of Wittgenstein, Thomas Nagel has made a convincing case in favour of the proposition that a self without the idea of being with someone else is inconceivable. See. T Nagel, The Possibility of Altruism (Princeton: Princeton UP, 1978), pp. 99-114.

34 L Wittgenstein, Philosophical Investigations (Harlow: Prentice Hall, 1973), \217: "If I have exhausted the justifications I have reached bedrock, and my spade is turned. Then I am inclined to say: "This is simply what I do."” 
this, it may be wise for proponents of contemporary analytical legal positivism to start getting used to the idea that there are moral truths and that the prima facie moral obligation to obey the law is one of them. In that case, however, it would certainly be worth considering further whether their supposedly descriptive accounts are really morally neutral, and hence also whether there is anything really positivistic left in legal positivism. 